\title{
Swedish Fifth and Sixth Graders' Motivational Values and the Use of ICT in Mathematics Education
}

\author{
Timo Tossavainen ${ }^{{ }^{*}}$, Ewa-Charlotte Faarinen ${ }^{1}$ \\ ${ }^{1}$ Lulea University of Technology, SWEDEN
}

Received 30 January 2019 • Revised 14 April 2019 • Accepted 15 April 2019

\begin{abstract}
Background: In Sweden, the introduction of new national curricula for primary and secondary schools has implied, for example, that programming has become a compulsory part of mathematics education since August 2018. We study Swedish fifth and sixth graders and the distributions of their motivational values related to studying mathematics with paper and pencil vs. with ICT.
\end{abstract}

Materials and methods: We examine, in the framework of Expectancy-value theory, data collected from 93 pupils using Student's t-test, correlation analysis and binary logistic regression analysis.

Results: Choosing between traditional and ICT-based approaches significantly affects the distribution of pupils' motivational values; pupils express higher attainment, utility, and cost values when studying mathematics with paper and pencil is concerned. In general, girls express higher motivation in mathematics than boys do. The utility value is the only significant predictor for the view that studying with ICT makes their learning of mathematics qualitatively better.

Conclusions: The Swedish fifth and sixth graders also motivated to study mathematics with ICT, yet the distributions of values differ across the genders; boys may benefit more from studying with ICT. Girls seem to need more and a different kind of encouragement than boys to find using ICT in mathematics education meaningful.

Keywords: expectancy-value theory of achievement motivation, ICT, mathematics, self-efficacy

\section{INTRODUCTION}

\section{Background and Research Questions}

The role of ICT in mathematics education is a hot topic in many countries. In Sweden, the introduction of new national curricula for primary and secondary schools has implied, for example, that programming has become a compulsory part of mathematics education since August 2018. Consequently, pupils in grades 7-9 are expected to learn how to write, analyse and even improve algorithms and code. However, as the summary of Swedish school and educational system below will show, there is a large variation across schools and teachers how well they are prepared for the implementation of the revised curriculum.

There are studies that report from the positive effect of the use of ICT on learning. For example, Biagi and Loi (2013) studied in 23 countries how students' scores in reading, mathematics, and science in OECD's PISA (Programme for International Student Assessment) 2009 test relate to the use of ICT. They found out - a little surprisingly - that the scores increase with the intensity of computer use for activities outside school such as playing games whereas the effect is opposite with the intensity of computer use for activities that are more closely related with school. Further, the number and diversity of computer-based activities had a positive correlation with students' proficiency in all three PISA domains in the vast majority of countries. An extensive meta-analysis, which

(C) 2019 by the authors; licensee Modestum Ltd., UK. This article is an open access article distributed under the terms and conditions of the Creative Commons Attribution License (http://creativecommons.org/licenses/by/4.0/). \timo.tossavainen@Itu.se (*Correspondence) $₫$ ewa-charlotte.faarinen@ltu.se 


\section{Contribution of this paper to the literature}

- This study examines eleven- and twelve-year old Swedish boys' and girls' motivation to study mathematics with paper and pencil vs. with ICT providing both similar and different findings compared to those from other cultures.

- We provide a less typical perspective by focusing on measuring the differences in the distributions of pupils' motivational values. Our results show that choosing between traditional and ICT-based studying approaches significantly affects the distribution. In our data, girls express clearly higher motivational values than boys, which is not usual in other cultures.

- Among the motivational values, the utility value is the only significant predictor for the view that studying with ICT makes the learning of mathematics qualitatively better.

covered 46 studies involving more than 36 thousand participants, concerning the effects of computer technology on primary and secondary students' learning of mathematics by Li and Ma (2010) also showed several statistically significant positive effects.

On the other hand, whether investments in ICT on a large scale really increase effectiveness and efficiency in mathematics education is a very complicated question. De Witte and Rogge (2014) studied this issue using the 2011 Trends in International Mathematics and Science Study (TIMSS) data. Their results show that the estimated impact of ICT depends highly on the criteria taken into account. Therefore, studies that aim at providing a deeper understanding about the issue with smaller data can be as valuable as larger surveys.

Our motivation for the present study is to examine how Swedish pupils value using ICT in mathematics education at the dawn of bringing programming into school. A recent study by Tossavainen and Hirsto (2018) from Finland, a neighbouring country having quite similar educational culture, showed that introducing iPads as an everyday tool in primary and lower secondary education has not generally increased pupils' motivation or performance in mathematics in their own opinion. However, the authors reported also from some findings suggesting that using iPads had slightly increased boys' interest in studying mathematics. Our aim is to find out whether the use of ICT has similar or different effects on the Swedish pupils' motivation in mathematics.

This article is based on data collected from 93 fifth and sixth graders in the Northern Sweden. In practice, the collection of data was conducted by Nea Lundmark who, under supervision of the first author, has also written a student thesis in Swedish from the preliminary analyses of the data (Lundmark, 2018). The results to be reported in this article are new. Our research questions are as follows.

(i) How do fifth and sixth graders' distributions of motivational values in mathematics differ from one another when studying with paper and pencil or with ICT is concerned?

(ii) Do boys and girls have similar motivational values of studying mathematics with paper and pencil vs. with ICT?

(iii) How do fifth and sixth graders' motivational values in mathematics relate to their opinion on whether or not they learn mathematics better with ICT?

The first and second questions are quite straightforward; we shall study them in the framework of Expectancyvalue theory (e.g., Wigfield \& Eccles, 2000). The last question is related to the item in the questionnaire that inquired a respondent's opinion on whether he/she learns mathematics qualitatively better with the aid of ICT.

\section{A Summary of Primary Mathematics Education in Sweden}

Parliament and government govern education in Sweden in general. There are several regulations for elementary school; one is the national curriculum (Skolverket, 2016). It defines goals, learning objectives, and guidelines for teaching in every subject including also mathematics.

In the national curriculum for primary mathematics, the digital aspects are addressed belonging to the central content in the areas of number perception and number usage, algebra, geometry, probability and statistics. The binary number system and how it is applied in digital technology are mentioned explicitly in the connection of number perception and number usage. The methods for calculations using written methods and digital tools are also mentioned here. Programming and algorithms in visual programming environments are included in algebra. Geometry contains the construction of objects, both with and without digital tools. In probability and statistics, tables and charts should be used for describing results from surveys with as well as without digital tools.

The national curriculum summarizes the goals of mathematics education in five abilities. Two of them emphasize the importance of the spoken language in mathematical communication and the other three an ability to formulate and solve problems, use and analyse mathematical concepts as well as use mathematical methods to solve routine tasks and make calculations. 
Every three years, the National Agency of Education undertakes a follow-up of ICT usage and ICT skills in schools. The last follow-up is from the school year 2015/2016 (Skolverket, 2016) and it shows that, in grades 4-6, the availability and usage of digital tools varies a lot across municipalities. On average, in elementary school, there are 1.8 students per computer or tablet. However, almost all teachers have access to a personal computer and a typical classroom is equipped also with a projector, document camera, and often also with programmable robots.

In grades 4-6, there is a high variation across schools which digital tools are really used. If a teacher is motivated to using technology, laboratory teaching materials are replaced with virtual manipulatives, document camera are used to show and discuss student solutions, projectors are used for response systems, robots to discuss geometric objects, dynamic programs to explore mathematics visually, Minecraft to work in three dimensions and so on. On the other hand, there are also classes where a teacher hardly uses other tools than a projector. A somewhat worrying fact is that only a very small percentage of Swedish teacher has taken a course in programming. Thus, the use of ICT in mathematics education varies a lot and depends on both availability of digital tools and teachers' choices and abilities to use them.

\section{THEORETICAL FRAMEWORK AND A REVIEW OF LITERATURE}

In general, ICT is a specific area of information technology that relates to digital devices used for communication and interaction with digital information. In this study, ICT includes digital tools and applications such as projectors, document cameras, computers, tablets, online tools, software and apps. In terms of software and applications, both those used by a teacher during lecture and those used by pupils while working in groups or independently are included.

In the national curriculum (Skolverket, 2016), Swedish National Agency for Education uses general expressions such as digital tools, digital media and digital technology instead of specifying ICT in more detail. This is probably due to the high rate of change and development of technological tools and solutions.

\section{Expectancy-value Theory and Self-efficacy}

Our theoretical framework is primarily based on Expectancy-value theory which is a theory of motivation that aims at explaining, for example, an individual's achievement in studying a subject in terms of beliefs about how well an individual will do the related activity and the extent to which they value the activity. It dates back to the early 1980s, yet the role of values has been studied, at least, since the 1950s (Eccles et al., 1983; Wigfield \& Eccles, 2000). In this context, ability beliefs are defined as the individual's perception of his or her current competence at a given activity. Theoretically, they are distinguished conceptually from expectancies for success so that ability beliefs focus on present ability and expectancies focus on the future. However, empirically these constructs are highly related (Wigfield \& Eccles, 2000, p. 70).

Within this framework, the values that constructs and operationalize the individual's motivation are often put in three or four categories: intrinsic values, attainment values, utility values and cost; sometimes the first two are put together since they represent the individual's inner motivation in a task whereas utility values stand for the extrinsic motivation.

More precisely, the intrinsic values in studying mathematics refer to interest in, or enjoyment of studying mathematics. The attainment values are related to the perceived importance of being good at mathematics, and the utility values to the perceived usefulness of knowing mathematics for short- and long-range goals. Cost, as the name of the construct indicates, refers to the cost of engaging in the activity; in this case, in studying mathematics. For more details, see, e.g., Eccles, Wigfield, Harold, and Blumenfeld (1993).

Some of the items in our questionnaire deal also with self-efficacy. Bandura (1982, p. 122) defined perceived selfefficacy as an individual's own judgement of how well one can execute courses of action required to deal with prospective situations. A central conclusion of the theory of self-efficacy is that those learners who have a high selfefficacy, for example, in mathematics, are likely to view difficult mathematical tasks as something attractive to overcome and master whereas learners with a low self-efficacy in mathematics try to avoid these tasks. Consequently, self-efficacy is often linked also to learning outcomes. For the challenges related to measuring selfefficacy, see Bandura (2012).

\section{Previous Research}

A survey of literature indicates that Tossavainen's and Hirsto's (2018) study is probably the first and sofar only one in the Nordic context focusing primarily on the impact of using ICT on primary pupils' motivation in mathematics. They explored 256 primary and lower secondary pupils' experiences from studying with tablet computers and found out an increase especially in boys' intrinsic values in studying mathematics, yet both boys and girls quite clearly disagreed with the claim that tablet computers had made it easier for them to learn 
mathematics. Further, girls clearly preferred to study mathematics with paper and pencil. These views seem to be quite firmly grounded since the utility value of using tablet computers in studying mathematics did not depend on the pupils' beliefs about their competence in mathematics.

In general, research on primary pupil motivation in mathematics with technology is relatively rare compared to research on secondary students' and pre-service teachers' relationship to the use of technology, yet some studies exist. For example, Hung, Huang, and Hwang (2014) investigated the effects of digital game-based learning on 68 Chinese fifth graders' self-efficacy, motivation, anxiety, and achievements in learning mathematics. They found out that a digital game-based learning model effectively promoted the students' learning achievement, self-efficacy, and motivation in mathematics. Torff and Tirotta (2010) examined with quite large data $(\mathrm{N}=773)$ to what extent the use of interactive whiteboard technology was associated with primary pupils' self-reported level of motivation in mathematics in the USA. In this study, the observed effect was however very weak. Further, Abidin, Mathrani, and Hunter (2018) studied the gender and the affective domain in learning mathematics with ICT in Indonesia. Their results also indicate that boys' views and attitudes towards using ICT in studying mathematics are somewhat more positive than those of girls, yet both genders expressed quite reserved views. The differences between the genders were especially rooted to self-efficacy and the intrinsic values.

Concerning older learners, Kebritchi, Hirumi, and Bai (2010) explored the effects of modern mathematics games on achievement and class motivation among 193 high school students and ten teachers from the USA. In an experiment that lasted 18 weeks, they noticed a significant improvement of the achievement of the experimental versus the control group. Nevertheless, no significant improvement was found in the motivation of the groups.

Similar mixed results can be found also in older reports from children's motivation and pre-service teachers' attitudes and readiness to use technology. Consequently, it is not surprising that critical analyses on the benefits of ICT in education may result in rather pessimistic conclusions, e.g., like that by Livingstone (2012, p. 9): “The difficulty in establishing traditional benefits, and the uncertainty over pursuing alternative benefits, raises fundamental questions over whether society really desires a transformed, technologically-mediated relation between teacher and learner." Yet meta-analyses like those of Biagi and Loi (2013) and Li and Ma (2010) indicate that using ICT must have some positive effect also on motivation as it has affected positively on learning results. In the light of the above literature review, a most plausible hypothesis is that using technology helps boys to find motivation in mathematics.

\section{METHOD}

\section{Data}

The questionnaire of this study was designed to collect information from fifth and sixth graders' motivational values related to studying mathematics and mother tongue in a traditional way and with the aid of ICT. In addition to some questions on a pupil's background, it contains sixteen claims on studying mathematics with paper and pencil and sixteen analogous claims on studying mathematics with ICT, see Appendix. Further, the pupil was also asked on the scale YES/NO whether or not he or she thinks that learning of mathematics is easier (e.g.," I learn what I have to learn with less time") or better (e.g., "I really understand what I learn and I remember it longer") with the aid of ICT.

The questionnaire contained an analogous set of questions related to mother tongue. In addition to asking pupils to answer the questionnaire, pupils' teachers were interviewed about how ICT has been used in their class.

The design of items in the questionnaire was based on Expectancy-value theory so that, at least, three items for each value were included. A couple of items were designed to measure a pupil's self-efficacy in mathematics. In each item, a pupil was supposed to answer on scale $1-5$ with 1 = "strongly disagree", $3=$ "neutral", and $5=$ "strongly agree" to what extend he or she agrees with the claim given in the item. Four questions contained also an opportunity to justify the answer with own words.

Concerning the number of the items in the questionnaire, it turned out that it was close to the maximum on which pupils were able to concentrate well.

\section{Participants and the Collection of Data}

This survey was conducted at three different schools in Northern Sweden. The collection of data was preceded by a letter of consent and information about the survey to the pupils and their parents. The purpose of the study was orally explained in the beginning of the lesson $(45 \mathrm{~min})$ that was reserved for filling in the questionnaire. At this point, the concept of ICT was explained and concretized to the participants. Further, the pupils were instructed how to use Likert scales for showing the agreement/disagreement with the claims given in the questionnaire. 
Table 1. The Cronbach alphas for the value constructs

\begin{tabular}{lcccc}
\hline & $\boldsymbol{N}_{\text {trad }}$ & $\boldsymbol{\alpha}_{\text {trad }}$ & $\boldsymbol{N}_{\boldsymbol{I C T}}$ & $\boldsymbol{\alpha}_{\boldsymbol{I C T}}$ \\
\hline Attainment $(1,3,4,5)$ & 92 & .67 & 92 & .60 \\
\hline Intrinsic $(6-8)$ & 93 & .90 & 93 & .84 \\
\hline Utility $(9,10,12)$ & 91 & .67 & 91 & .64 \\
\hline Cost $(13,14,16)$ & 92 & .52 & 92 & .42 \\
\hline
\end{tabular}

Table 2. Means and standard deviations for the values $(\mathrm{N}=93)$

\begin{tabular}{lcccc}
\hline & $\overline{\boldsymbol{x}}_{\text {trad }}$ & $\boldsymbol{S D}_{\text {trad }}$ & $\overline{\boldsymbol{x}}_{\text {ICT }}$ & $\boldsymbol{S D}_{\text {ICT }}$ \\
\hline Attainment & 4.35 & .62 & 4.16 & .59 \\
\hline Intrinsic & 3.49 & 1.11 & 3.57 & .97 \\
\hline Utility & 4.12 & .76 & 4.02 & 1.35 \\
\hline Cost & 3.36 & .83 & 3.27 & .78 \\
\hline
\end{tabular}

The participants are from five classes; a total of 156 pupils were asked to participate and 93 did so. The loss was due to a missing letter of consent or a pupil's absence or choice; the participation was voluntary. The participating pupils answered the questionnaire anonymously.

The interviews of teachers revealed that ICT has been used during the mathematics lessons one or two times a week in their classes. In addition to a teacher using a projector and smartboard, typically, pupils have used tablet computers for training calculation skills with various applications. Sometimes, computers are used for the presentation of data such as diagrams. Most often, a pupil works on his or her own with a computer, only one class has used computers for collaborative studying. Programming has also been introduced in one class.

To sum up, the respondents seem to have a quite wide experience from using ICT in mathematics education which increases the validity of our data. Also, the schools and classes that participated in the study are typical for Swedish schools, and there occurred no incidents during the data collection that would make us to question the reliability of pupils' responses.

\section{Analyses}

We analysed our data using SPSS Statistics version 25. In addition to computing standard descriptive measures for the concerned variables, the following methods were applied: Student's independent samples and paired samples t-tests, Pearson correlation analysis, Cross tabulation with Chi-Square test, and binary logistic regression analysis. Further, the Cronbach alphas were computed in order to estimate the dimensionality of the sum variables that represent the latent motivational variables.

\section{RESULTS}

We begin by reporting from the reliability analysis of the sum variables standing for the values. Table 1 shows the Cronbach alphas for these constructs. Attainment is the mean of four scales and the other constructs are the means of three scales, respectively. The scales standing for each construct are indicated in Table 1; for the content of them, see Appendix.

Table 1 shows that the first three constructs are rather well one-dimensional but the last one is only to a lesser degree. We decided to use the sum variable shown in Table 1, yet an alternative solution would have been to use a single item which most explicitly represents the cost value. Actually, in order to examine the quality of our instrument, we also conducted several explorative factor analyses with the generalized least squares extraction method based on eigenvalues greater than one. These resulted to a three-factor model for the scales related to the traditional teaching approach and a four-factor model when scales related to teaching with ICT were concerned. These models support the conclusion that our instrument measures well the intrinsic values, rather well the utility values and satisfactorily the attainment values and the cost; some of the scales representing these values were loaded equally strong from two or three factors. Two plausible reasons for this outcome are the fact that value variables often correlate with one another (e.g., Tossavainen \& Juvonen, 2015) and the size of our data is quite small compared to the number of Likert scales.

Table 2 provides an answer to the first research question. A general finding in Table 2 is that the Swedish fifth and sixth graders have high attainment and utility values for both traditional and ICT supported approaches to studying mathematics. As already said, these are typically interpreted to represent outer (or extrinsic) motivation while the intrinsic values and the cost values stand more for an individual's inner motivation. Grouping the values in this way, the means for the sum variables representing the outer motivation are highly significantly higher than those representing the inner motivation in the paired-samples $t$-tests $(t(92)<11.18-11.79, p<.001)$ irrespective of that whether studying with paper and pencil or with ICT is concerned. 
Table 3. The distributions of motivational values across the grades $\left(N_{5 t h}=50, N_{6 t h}=43\right)$

\begin{tabular}{lcccccccc}
\hline & $\boldsymbol{A}_{\text {trad }}$ & $\boldsymbol{A}_{\boldsymbol{I C T}}$ & $\boldsymbol{I}_{\text {trad }}$ & $\boldsymbol{I}_{\boldsymbol{I C T}}$ & $\boldsymbol{U}_{\text {trad }}$ & $\boldsymbol{U}_{\boldsymbol{I C T}}$ & $\boldsymbol{C}_{\text {trad }}$ & $\boldsymbol{C}_{\boldsymbol{I C T}}$ \\
\hline Mean (5th grade) & 4.58 & 4.31 & 3.81 & 3.69 & 4.41 & 4.19 & 3.62 & 3.48 \\
\hline Std. dev. & .46 & .51 & 1.03 & .91 & .59 & .65 & .73 \\
\hline Mean (6th grade) & 4.09 & 3.98 & 3.12 & 3.43 & 3.79 & 3.81 & 3.05 & 3.04 \\
\hline Std.dev. & .69 & .63 & 1.11 & 1.04 & .84 & .82 & .86 & .80 \\
\hline
\end{tabular}

Table 4. Means and standard deviations for boys $\left(\mathrm{N}_{\text {boy }}=50\right)$ and girls $\left(\mathrm{N}_{\text {girl }}=43\right)$

\begin{tabular}{lcccccccc}
\hline & $\overline{\boldsymbol{x}}_{\text {boy }}$ & $\boldsymbol{S D}_{\text {boy }}$ & $\overline{\boldsymbol{x}}_{\text {girl }}$ & $\boldsymbol{S D}_{\text {girl }}$ & $\overline{\boldsymbol{y}}_{\text {boy }}$ & $\boldsymbol{S D}_{\text {boy }}$ & $\overline{\boldsymbol{y}}_{\text {girl }}$ & $\boldsymbol{S D}_{\text {girl }}$ \\
\hline Attainment & 4.28 & .67 & 4.44 & .56 & 4.13 & .57 & 4.20 & .61 \\
\hline Intrinsic & 3.29 & 1.08 & 3.74 & 1.12 & 3.58 & 1.08 & 3.57 & 1.12 \\
\hline Utility & 3.96 & .83 & 4.31 & .66 & 3.94 & .76 & 4.10 & .75 \\
\hline Cost & 3.09 & .77 & 3.67 & .81 & 3.07 & .77 & 3.52 & .74 \\
\hline
\end{tabular}

$x=$ traditional approach, $y=$ ICT supported approach

The main result in Table 2 is that the distributions of pupils' motivational values are different depending on that whether studying mathematics with paper and pencil or with ICT is concerned. In the paired-samples t-test, the mean difference in the first pair is highly significant $(t(92)=3.67, p<.001)$ and, in the third and fourth pairs, significant $(t(92)=2.10-2.48, p<.05)$. The effect size (Cohen's d) for the first mean difference is .32 which is already remarkable yet not large. For the other significant mean differences, the effect size is less than . 2 which is a common limit for a small effect. This mainly due to the larger standard deviations.

A remarkable detail is that, for the intrinsic value, the observed mean difference is positive for using ICT. The difference is not statistically significant but one may interpret it indicating that using ICT possibly increases some pupils' interest and joy in mathematics; Table 4 will provide more evidence for this conclusion. Perhaps, the most interesting finding in Table 2 is that the use of ICT does not increase pupils' willingness to invest more time and effort to studying mathematics. The cost value remains at relatively low levels both for the traditional and ICT supported studying approaches. Table 4 shows that this is the case even with boys.

The mean differences in Table 2 can be summarized by saying that the Swedish students have a slightly reserved view of using ICT in mathematics, yet it is evident that they are not against it.

To complete our answer to the first research question, we consider also how the distributions of the motivational values differ between the grades and whether age and grade interact in a statistically significant way. For the latter question, we conducted multivariate analysis of covariance which showed that the interaction gender*age was not a significant variable in any of these general linear models ( $p>.05)$.

Table 3 summarizes that the sixth graders express clearly lower motivational values irrespective of that whether studying with paper and pencil or with ICT is concerned. In the independent samples t-test, the mean differences between the grades are statistically significant for every value, except for the intrinsic value with ICT, cf. Tables 2 and 4.

Table 4 shows that the distributions of the motivational values in mathematics are also different across the genders. First, the means for the girls are higher than those for the boys in every value when the traditional teaching is concerned. The independent samples t-test shows that the differences are statistically significant for the cost value $(t(91)=-3.50, p<.01)$ and the utility value $(t(91)=-2.20, p<.05)$.

Concerning studying with ICT, the mean differences between genders are smaller compared with the means for the traditional teaching. The smaller differences are now mostly due to that that all means decrease for girls, and for boys, they remain almost the same or even increase. Therefore, the only significant difference between the genders is related to the cost value; girls are still more willing to invest extra time and effort to studying mathematics, yet neither group is very enthusiastic about it. An important finding is that the most significant change in the values is related to boys and the intrinsic value. Boys express higher intrinsic motivation in mathematics $(t(49)=-3.15, \mathrm{p}<.01)$ when ICT is used.

The respondents were also asked on the scale YES/NO about their view whether or not they think that they learn mathematics easier (e.g., with less time) or better (e.g., "I really understand what I learn and I remember it longer") with the aid of ICT. A similar item was used also by Abidin, Mathrani and Hunter (2018). The distributions of their answers are given in Table 5. Boys are more positive about both claims about the help that ICT provides for their learning of mathematics; a majority of them agrees with both claims. Only a third of girls agree with the former claim and a fourth of them with the latter proposition. If we look at the distributions as whole, approximately a half of the participating pupils express that studying with ICT makes the learning of mathematics easier (faster) but only a little more than a third of them agrees that ICT helps them to learn mathematics better. 
Table 5. Boys' and girls' experience from the aid of ICT for the learning of mathematics

\begin{tabular}{|c|c|c|c|c|c|c|}
\hline & \multicolumn{2}{|c|}{ I learn easier with ICT } & \multicolumn{4}{|c|}{ I learn better with ICT } \\
\hline & No & Yes & Total & No & Yes & Total \\
\hline Boy & 19 & 31 & 50 & 22 & 25 & 47 \\
\hline Girl & 29 & 14 & 43 & 30 & 10 & 40 \\
\hline \multirow[t]{2}{*}{ Total } & 48 & 45 & 93 & 52 & 35 & 87 \\
\hline & \multicolumn{2}{|c|}{$\chi(1)=8.02, p<.01$} & \multicolumn{4}{|c|}{$\chi(1)=7.14, p<.01$} \\
\hline
\end{tabular}

Table 6. Items with a statistically significant mean difference

\begin{tabular}{|c|c|c|c|c|}
\hline & $\bar{x}_{Y E S}$ & $S D_{Y E S}$ & $\bar{x}_{N O}$ & $S D_{N O}$ \\
\hline 5. I am proud of myself for what I have learnt in mathematics & 3.74 & .76 & 4.23 & 1.01 \\
\hline 8. I think that it is interesting to do exercises in mathematics & 3.17 & 1.07 & 3.77 & 1.22 \\
\hline 9. I am going to have use for the mathematics I have learnt in school & 3.94 & 1.00 & 4.46 & .83 \\
\hline 11. I study because I have to learn mathematics & 3.86 & 1.24 & 3.21 & 1.59 \\
\hline 12. I study mathematics because it helps me to find a job in the future & 4.29 & 1.13 & 4.73 & .60 \\
\hline
\end{tabular}

Table 7. Binary logistic regression model

\begin{tabular}{lcccc}
\hline & B & Std.err. & Sig & Exp(B) \\
\hline Constant & -2.459 & 1.255 & .050 & 0.085 \\
\hline Utility & .700 & .303 & .021 & 2.014 \\
\hline
\end{tabular}

Nagelkerge R Square $=.09$

The Pearson correlation between the items in Table 5 is $.50(p<.001)$. This is quite high and stands for a large effect, but one might have expected that these variables had even a larger co-variation. The foremost reason for this is that 15 out of those 43 pupils who answered positively in the first item answered negatively in the second one. So, fifth and sixth graders seem to clearly acknowledge the difference between an experience from learning being easy and experience from learning being effective.

Pupils who judged these claims negatively explained, e.g., by saying: "In my opinion, it is hard and stressful to study with ICT" and "I think that it is easier with pen and paper. When we use iPads, it is often [too little] time and a bit more stressful". Those who expressed that they learn mathematics better with the aid of ICT motivated their answer most often by referring to having more fun with technology and that it is more interesting to study mathematics in this way and boring with paper and pencil. For example, "I think that mathematics may be a little boring sometimes, so, I would like to have some variation, and then one wishes that one could use more amusing tools and facilities."

Concerning the last research question, we first divided the participants into two groups $\left(N_{Y E S}=35, N_{N O}=52\right.$, cf. Table 4) according to that whether or not they agree with the claim no. 19 "I learn mathematics better (e.g., I really understand what I learn and I remember it longer) with the aid of ICT" and then compared the group means and standard deviations for each item using independent samples t-test, see Appendix. Table 6 shows means and standard deviations for those items for which the mean difference is statistically significant $(\mathrm{p}<.05)$.

Table 6 demonstrates in which way those respondents who disagree with the claim no. 19 have a higher motivation and self-efficacy in mathematics. Indeed, items 5 and 8 are related to self-efficacy and the intrinsic value in mathematics. Items 9 and 12 represent the utility value. Item 11 stands for the extrinsic motivation; this is the only item for which the mean is higher in the group that agrees with the claim. As a summary, one can interpret that those pupils, who do not expect that using ICT improves their learning of mathematics, have a stronger inner motivation in mathematics than those pupils who expect to gain from using ICT in studying mathematics. The latter pupils' motivation in mathematics is clearly more extrinsic than intrinsic, e.g., the mean difference between items 8 and 12 in this group is highly significant $(\mathrm{t}(34)=-4.90, \mathrm{p}<.001)$.

To conclude this section, in Table 7, we report from a binary logistic regression analysis that was performed with method Forward: Conditional in order to see whether any of the motivational values is effective in predicting how pupils answer in the claim no. 19. The analysis revealed that, in our data, Utility is such a value and there are no other values. Nagelkerke R Square (which is often interpreted as the rate of explained variation) is now 0.09 and the model predicts correctly $69 \%$ of the cases. For the null model, the percentage is 59.8 , so, there is a significant improvement. Consequently, one can conclude that the stronger the view that it is useful to know mathematics is, the more probably a pupil thinks that he or she learns mathematics better with the aid of ICT.

\section{DISCUSSION AND CONCLUSIONS}

There are studies that show that pupils' motivation in mathematics, but also in other subjects, begins to decrease at the age of 11-12 (e.g., Tossavainen \& Juvonen, 2015). Table 3 shows that this is the case also in Sweden. If the 
participants are considered as a single group, the respondents' intrinsic motivation in mathematics is however high both with and without aid of ICT (Tables 2 and 4) compared to the measures from many international assessments and, especially, to a similar study conducted in Finland (Tossavainen \& Hirsto, 2018). Our conclusion is that Swedish pupils are especially neither for nor against using ICT in studying mathematics but they are positively realistic and do not expect a miracle to happen with ICT.

In general, our findings related to Tables 2-5 show both similarities and differences with the results in Tossavainen \& Hirsto (2018) and, on the overlapping issues, in Abidin, Mathrani, and Hunter (2018). In both of these studies, a difference between girls' and boys' motivation to study mathematics with ICT was found. However, in Sweden the difference is remarkably large in favour of girls. But, as especially girls are more reserved when studying with ICT is concerned, it seems that girls need more and a different kind of encouragement to find using ICT meaningful in mathematics education. This conclusion gains support also from the item measuring pupils' opinion on whether using ICT makes learning in mathematics better; it was used both in the questionnaire of the present study and that by Abidin, Mathrani, and Hunter (2018). In our study, the percentage of boys and girls who see that ICT makes their learning better in mathematics are 53 and 33, respectively; in the latter study, they are 50 and 25, respectively (Abidin, Mathrani \& Hunter, 2018, p. 274).

Tables 2, 4, and 6 indicate clearly that pupils that prefer a traditional approach to studying mathematics show a higher intrinsic motivation in mathematics and the pupils who perceive having benefitted from studying with ICT express more extrinsic motivation. The previous group has a somewhat higher motivation in mathematics in general but a more appropriate conclusion is to say that technologically and traditionally oriented pupils have different kinds of motivation in mathematics; the traditionally oriented have more intrinsic and the technologically oriented have more extrinsic motivation in mathematics.

Our data do not directly allow us to answer what is the possible reason for that. Something can however be concluded from the open answers where pupils explained their judgement of this item and the item which concerned whether learning is easier with ICT. It seems that technologically oriented pupils think that the traditional teaching of mathematics is more or less boring but giving a possibility study with ICT they learn something - mathematics or how to use ICT in the context of mathematics - that they consider being useful to them.

The result from the binary logistic regression analysis supports this conclusion, too. The direct interpretation of the model is that the utility values related to studying mathematics encourages pupils also to view that learning mathematics with the aid of ICT is more effective. The model can however be interpreted also so that, if studying mathematics with ICT is a natural thing for a pupil, then the pupil values the aid provided by ICT the more, the higher utility value he or she has of knowing mathematics.

If the implementation of programming in mathematics education is concerned, succeeding in it depends highly on the way how new digital learning environments are taken in use. Teacher's attitude and ability to motivate with concrete and elucidating examples for what purpose programming is introduced are fundamental. Similar conclusions have been reached also elsewhere. For example, Genlott and Grönlund (2016) suggests that, in order to benefit from the use of ICT, it must be integrated functionally and with care into the pedagogical design of activities. Also, Drijvers (2015) say that crucial factors for the successful use of ICT in mathematics education include the design of the digital tool and corresponding tasks exploiting the tool's pedagogical potential, the role of the teacher, and the educational context. Further, the findings of Kebritchi, Hirumi, and Bai (2010) encourage to use mathematical games as an aid of integrating mathematics education and the use of technology even though their experiment did not increase motivation in mathematics.

A plausible approach to using ICT in mathematics education, which also applies well to the implementation of programming in mathematics education, is introduced by Haapasalo (2007). He suggests that instead of speaking about 'implementing modern technology into classroom' it might be more appropriate to speak about 'adapting mathematics teaching to the needs of information technology in modern society'. By this he means that mathematics education with ICT could focus more on informal than formal mathematics and this should be done within the framework of activities that have proved to be sustainable in the history of human thinking processes and making of mathematics. A similar approach is discussed by Tossavainen and Pehkonen (2013) who introduced the framework of didactical mathematics as an approach to be used in mathematics teacher education in order to build bridges between school mathematics and academic mathematics.

As a pupil's citation above showed, some pupils are worried about that using ICT takes more time than a traditional approach to studying mathematics. Using programming in mathematics education can help to solve this issue. There are no requirements that a pupil should write full programs from nothing. Depending on the topic, it may be an advantage to use tinkering, where the pupil gets parts of a program as such for testing and identifying through experimentation how the program is structured, and thus he or she reaches a deeper understanding of the mathematical content. Again, the odds for succeeding depend more on the pedagogical approach and a teacher's choices than on ICT itself. 


\section{ACKNOWLEDGEMENTS}

We thank Nea Lundmark for collecting the data.

\section{REFERENCES}

Abidin, Z., Mathrani, A., \& Hunter, R. (2018). Gender-related differences in the use of technology in mathematics classrooms: Student participation, learning strategies and attitudes. The International Journal of Information and Learning Technology, 35(4), 266-284. https:/ / doi.org/10.1108/IJILT-11-2017-0109

Bandura, A. (1982). Self-efficacy mechanism in human agency. American Psychologist, 37(2), $122-147$. https://doi.org/10.1037/0003-066X.37.2.122

Bandura, A. (2012). On the Functional Properties of Perceived Self-Efficacy Revisited. Journal of Management, 38(1), 9-44. https:/ / doi.org/10.1177/0149206311410606

Biagi, F., \& Loi, M. (2013). Measuring ICT use and learning outcomes: evidence from recent econometric studies. European Journal of Education, 48(1), 28-42. https:/ / doi.org/10.1111/ ejed.12016

DeWitte, K., \& Rogge, N. (2014). Does ICT matter for effectiveness and efficiency in mathematics education? Computers E Education, 75, 173-184. https:/ / doi.org/10.1016/j.compedu.2014.02.012

Drijvers P. (2015). Digital Technology in Mathematics Education: Why It Works (Or Doesn't). In S. Cho, Selected Regular Lectures from the 12th International Congress on Mathematical Education (pp. 135-151). Cham: Springer. https:/ / doi.org/10.1007/978-3-319-17187-6_8

Eccles, J. S., Adler, T. F., Futterman, R., Goff, S. B., Kaczala, C. M., Meece, J., \& Midgley, C. (1983). Expectancies, values and academic behaviors. In J. T. Spence, Achievement and achievement motives (pp. 75-146). San Francisco, CA: W. H. Freeman.

Eccles, J., Wigfield, A., Harold, R. D., \& Blumenfeld, P. (1993). Age and gender differences in children's self- and task perceptions during elementary school. Child Development, 64(3), 830-847. https:/ / doi.org/10.1111/j.1467-8624.1993.tb02946.x.

Genlott, A. A., \& Grönlund, A. (2016). Closing the gaps - Improving literacy and mathematics by ict-enhanced collaboration. Computers \& Education, 99, 68-80. https:/ / doi.org/10.1016/j.compedu.2016.04.004

Haapasalo, L. (2007). Adapting mathematics education to the needs of ICT. The Electronic Journal of Mathematics and Technology, 1(1), 1-10.

Kebritchi, M., Hirumi, A., \& Bai, H. (2010). The effects of modern mathematics games on mathematics achievement and class motivation. Computers $\mathcal{E}$ Education, 55(2), 427-443. https:/ / doi.org/10.1016/j.compedu.2010.02.007

Li, Q., \& Ma, X. (2010) A meta-analysis of the effects of computer technology on school students' mathematics learning. Educational Psychology Review, 22(3), 215-243. https:/ / doi.org/10.1007/s10648-010-9125-8

Lundmark, N. (2018). IKT i matematikundervisning. Hur påverkar det elevers syn på sin motivation? [ICT in mathematics education. How does it influence on pupils' view of their motivation?] Master thesis. Lulea: Lulea University of Technology.

Skolverket. (2016). Curriculum for elementary school, preschool class and after-school center 2011 (Revised 2016). Stockholm: Swedish National Agency for Education.

Torff, B., \& Tirotta, R. (2010). Interactive whiteboards produce small gains in elementary students' self-reported motivation in mathematics. Computers $\mathcal{E}$ Education, 54, 379-383. https:/ / doi.org/10.1016/j.compedu.2009.08.019

Tossavainen, T. \& Juvonen, A. (2015). Finnish primary and secondary students' interest in music and mathematics relating to enjoyment of the subject and perception of the importance and usefulness of the subject. Research Studies in Music Education, 37(1), 107-121. https:/ / doi.org/10.1177/1321103X15589259

Tossavainen, T. \& Pehkonen, E. (2013) Three kinds of mathematics: scientific mathematics, school mathematics and didactical mathematics. Far East Journal of Mathematical Education, 11(1), 27-42.

Tossavainen, T., \& Hirsto, L. (2018). Tablet computers and Finnish primary and lower secondary students' motivation in mathematics. In E. Norén, H. Palmer \& A. Cooke, Nordic Research in Mathematics Education. Papers of NORMA 17 The Eighth Nordic Conference on Mathematics Education Stockholm, May 30 - June 2, 2017 (pp. 59-67). Gothenburg: Swedish Society for Research in Mathematics Education.

Wigfield, A., \& Eccles, J.S. (2000). Expectancy-value theory of achievement motivation. Contemporary Educational Psychology, 25(1), 68-81. https:/ / doi.org/10.1006/ceps.1999.1015 


\section{APPENDIX}

\section{The Likert Items in the Questionnaire that are Related to Studying Mathematics}

In each item, a pupil was asked to respond on the scale 1-5 to the given claim concerning

a) mathematics with paper and pencil,

b) mathematics with ICT,

respectively. The claims are

1. It is important for me to get high grade or other commendable feedback for my performance $\mathbf{a} / \mathbf{b}$

2. It feels bad if I am not able to solve an exercise in $\mathbf{a} / \mathbf{b}$

3. I want that my parents will be proud of me for my performance in $\mathbf{a} / \mathbf{b}$

4. I want that my teacher is proud of me for my performance in $\mathbf{a} / \mathbf{b}$

5. I am proud of myself for what I have learnt in $\mathbf{a} / \mathbf{b}$

6. I like to study $\mathbf{a} / \mathbf{b}$

7. I feel joy when we the next lecture will be $\mathbf{a} / \mathbf{b}$

8. I think that it is interesting to do exercises in $\mathbf{a} / \mathbf{b}$

9. I am going to have use of $[\mathrm{a} / \mathrm{b}]$ that I have learnt in school.

10. I have learnt lot of things in $[\mathbf{a} / \mathbf{b}]$ that I am going to use in the future.

11. I study because I have to know $\mathbf{a} / \mathbf{b}$

12. I study $[\mathbf{a} / \mathbf{b}]$ because it helps me to find a job in the future.

13. I think that I benefit from learning something new in $[\mathbf{a} / \mathbf{b}]$ even though it is difficult and takes a lot of time.

14. I think that I benefit from learning something new in $[a / b]$ even though it may make me feel not good (e.g. I feel stressed or that I am not good enough)

15. I spend more energy on studying $[\mathbf{a} / \mathbf{b}]$ than I get out of it.

16. I could voluntarily suspend my favourite hobby in order to study $\mathbf{a} / \mathbf{b}$

\section{http://www.ejmste.com}

